\title{
What factors are most influential in governing stemflow production from plantation-grown teak trees?
}

\section{Authors}

Nobuaki Tanaka ${ }^{1 *}$, Delphis Levia ${ }^{2,3}$, Yasunori Igarashi ${ }^{3}$, Natsuko Yoshifuji $^{4}$, Katsunori Tanaka $^{5}$, Chatchai Tantasirin ${ }^{6}$, Kazuki Nanko ${ }^{4}$, Masakazu Suzuki ${ }^{7}$, Tomo'omi Kumagai ${ }^{3}$

\section{Author affiliations}

${ }^{1}$ Ecohydrology Research Institute, The University of Tokyo Forests, Graduate School of Agricultural and Life Sciences, The University of Tokyo, Seto, Aichi 489-0031, Japan

${ }^{2}$ Departments of Geography \& Plant and Soil Sciences, University of Delaware, Newark, DE 19716, USA

${ }^{3}$ Hydrospheric Atmospheric Research Center, Nagoya University, Nagoya, Aichi 464-0801, Japan

${ }^{4}$ Department of Meteorological Environment, Forestry and Forest Products Research Institute, Tsukuba, Ibaraki, 305-8687 Japan

${ }^{5}$ Department of Environmental Geochemical Cycle Research, Japan Agency for Marine-Earth Science and Technology, Kanazawa-ku, Yokohama 236-0001, Japan

${ }^{6}$ Faculty of Forestry, Kasetsart University, Chatuchak, Bangkok 10900, Thailand

${ }^{7}$ Graduate School of Agricultural and Life Sciences, The University of Tokyo, Bunkyo-ku, Tokyo 113-0023, Japan

\section{*Corresponding author}

TEL: +81 56182 2371, FAX: +81561852383

Email address: tanaka@uf.a.u-tokyo.ac.jp (N. Tanaka) 
1 Abstract Stemflow (SF) has been recognized as an important process delivering water to

2 spatially localized areas of the forest floor. Based on almost six years of daily SF data from

3 nine teak trees in a Thai plantation, together with detailed above-canopy meteorological data

4 and daily leaf area index (LAI) data, this study sought to better understand how specific biotic

5 and abiotic factors affect both individual and stand-scale SF production from teak trees.

6 Specifically, the factors affecting stemflow funneling ratio (SFFR) at individual and stand

7 scales were analyzed and compared by means of boosted regression tree (BRT) analysis. The

8 largest variation of SFFR among individual teak trees was observed in the leafed state. For

9 trees taller than average, the BRT analysis revealed that vapor pressure deficit during rain was

10 the most influential factor affecting SFFR. Vapor pressure deficit had a negative influence on

11 SFFR, implying significant control of evaporative demand during rain. In contrast, for trees

12 shorter than the average, rain duration $\left(R_{\mathrm{D}}\right)$ was the most influential variable, having a positive

13 correlation with SFFR. The stand-scale BRT analysis for all nine teak trees demonstrated that

$14 R_{\mathrm{D}}$ was the most influential factor affecting SFFR (exerting positive influence) but that an

15 array of other factors (both abiotic and biotic) played intricate and complex roles in governing

16 SFFR. The effect of LAI on SFFR was complicated and varied greatly among individual teak

17 trees. It is possible that spatially heterogeneous flowpaths of intercepted water inside the teak canopy, which could be a product of the large-sized mature leaves of teak, may account for the tree-to-tree variation in the responses of SFFR to changing LAI. Although our study focused on teak trees, the demonstrated physically-based mechanistic explanations of stemflow production could apply to other even-aged deciduous forests and monospecific plantations.

22 Keywords Stemflow, Deciduous forest, Monospecific plantation, Leaf area index, Leafing phenophase 


\section{Introduction}

Stemflow usually results from rain falling onto the forest canopy and running downward along the branches and tree trunk, where it eventually reaches the tree-forest floor interface. Because stemflow typically accounts for 3-10\% of incident rainfall (Levia and Frost, 2003), it has received less attention from the standpoint of the stand scale canopy water budget. Stemflow, however, has been increasingly recognized as an important process delivering water, solute and particulate fluxes to spatially localized areas of the forest floor (Levia and Germer, 2015), effectively functioning as 'hot spots' (McClain et al., 2003) of water and solute fluxes into the forest soil. It is likely that stemflow-induced hot spots are directly connected to the root system of trees (Johnson and Lehmann, 2006), thereby playing important roles in hillslope hydrology (Liang et al., 2007, 2011), groundwater recharge (Tanaka, 2011), soil chemical properties (Gersper and Holowaychuk, 1971; Chang and Matzner, 2000), soil moisture distribution (Durocher, 1990; Germer, 2013) and the fate of fungal conidia transported from the canopy (Gönczöl and Révay, 2004; Sridhar and Karamchand, 2009).

Stemflow volume varies considerably for individual trees (Levia, 2004; Iida et al., 2010) as a function of both biotic and abiotic factors (Levia and Frost, 2003). Biotic factors affecting stemflow production range from bark microrelief (Brown and Barker, 1970; Van Stan and Levia, 2010; Carlyle-Moses and Schooling, 2015) to crown length (Iida et al., 2010), woody:foliar biomass ratio (Levia et al., 2015), and tree size (Levia et al., 2010; Siegert and Levia, 2014). Abiotic factors, such as within-event rainfall intensity profile (Dunkerley, 2014), hourly vapor pressure deficits (Staelens et al., 2008), and season (Helvey and Patric, 1965; Staelens et al., 2011) also partially govern stemflow yield. Among the array of metrics for evaluating stemflow water flux to the soil (Levia and Germer, 2015), stemflow funneling ratio per basal area (SFFR, unitless), originally defined by Herwitz (1986), is a straightforward 
metric indicating the degree of water flux localization near the tree trunk in comparison with other areas of the forest floor. SFFR enables insights into the effect of differing meteorological conditions on stemflow generation. In fact, SFFR was successfully used in a number of studies comparing stemflow yield patterns between differing species and individuals with different canopy structure and bark morphology (e.g., Carlyle-Moses and Price, 2006; Levia et al., 2010; Siegert and Levia, 2014).

Even though stemflow can play an important role in the cycling of water and nutrients, stemflow studies on teak (Tectona grandis Linn. f.), a commercially valuable tropical deciduous hardwood, often cultivated in plantations (Krishnapillay, 2000), are rather limited.

With a dramatic increase in the number and areal extent of teak plantations (currently occupying a minimum of 4.3 million ha over the tropics according to Kollert and Cherubini, 2012), there is a pressing need to better understand stemflow production dynamics by teak trees. To date, most studies on teak stemflow have focused on its fraction of incident rainfall for a specific stand and they reported a large variability in the fractions ranging from $2 \%$ to 15\% (Castillo, 1986; Charoensuk et al., 1989; Srinivasan et al., 2012; Dabral and Subba Rao, 1968; Okali, 1980; Buvaneswaran et al., 2003). The variability may be caused by differences in the aforementioned biotic and abiotic factors among plantations. Therefore, in addition to the case studies listed above, a detailed analysis as to how a suite of biotic and abiotic factors affect teak stemflow generation is necessary in order to draw a more general conclusion of the characteristics of teak stemflow.

It is well known that deciduous tree species produce larger stemflow quantities in the leafless state than the leafed state (Helvey and Patric, 1965; Dolman, 1987; Neal et al., 1993; Park et al., 2000; Herbst et al., 2008; Staelens et al., 2008; Siegert and Levia, 2014). Exceedingly little work, however, has gone beyond the dichotomous comparison of stemflow production 
between leafed and leafless states. In fact, to our knowledge, there has been no study examining stemflow of deciduous tree species in relation to a detailed daily time series of leaf area index $\left(\mathrm{LAI}, \mathrm{m}^{2} \mathrm{~m}^{-2}\right)$. Given the importance of the presence and absence of leaves on stemflow production, a more detailed analysis on any effects of daily LAI changes on stemflow production is warranted. This is especially true for deciduous trees during the leafing phenophase and trees species with large leaves, such as teak.

Based on a combination of long-term stemflow data from a set of experimental teak trees in a Thai teak plantation, detailed above-canopy meteorological data, and daily LAI data, this study examines which biotic and abiotic factors most influence stemflow production. To broaden our knowledge on the effects of LAI on stemflow production and fill a void in the current literature, specific emphasis is placed on the influence of temporal variation in daily LAI and its impact on SFFR. The influence of various biotic and abiotic factors on stemflow production are examined at both the stand-scale and individual tree scale. Although the experimental teak trees were grown in the same plot and are of the same age with similar management strategies, there were some structural differences among the teak trees with regard to size and branching geometry. Thus, this study advances our knowledge of intraspecific variation of stemflow generation which is quite important for monospecific plantations of economically valuable tree species. Specific objectives of the present study were to: (i) compare stemflow production of teak trees in the leafed state with that in the leafless state, using a conventional regression analysis; (ii) clarify SFFR magnitude of teak trees as an index of water flux localization near the tree trunk; (iii) understand the influence of various biotic and abiotic factors on stemflow production at both individual tree-scale; and (iv) the stand-scale. These objectives provide the structural sub-headings used in the Results and Discussion sections. Our results should appeal to other hydrologists examining stemflow production in even-aged deciduous forests and 
monospecific plantations. Insights gained from the present study would improve our knowledge of stemflow production in teak that may be useful to improve forest management strategies.

\section{Materials and methods}

\subsection{Site description}

Field work was conducted in an even-aged teak plantation in Mae Mo district, Lampang province, northern Thailand $\left(18^{\circ} 25^{\prime} \mathrm{N}, 99^{\circ} 43^{\prime} \mathrm{E} ; 380 \mathrm{~m}\right.$ asl). Teak saplings were planted in 1968 by the Thai Forest Industry Organization, with a stand density of 440 trees $^{-1} \mathrm{as}^{-1}$ of November 2005. Mean ( \pm 1 SD) stem diameter at breast height $(\mathrm{dbh}, \mathrm{cm})$ and tree height were $22.4 \mathrm{~cm}( \pm 7.3)$ and $19.9 \pm 3.5 \mathrm{~m}(n=308)$, respectively (as of November 2005).

The climate is largely governed by the Asian Monsoon, with two notable seasons: a wet season, occurring from roughly May to October, and a dry season, spanning from approximately November to April. Mean annual rainfall was 1230.9 mm (1986-2010). Mean annual air temperature was $25.4{ }^{\circ} \mathrm{C}(2001-2010)$, with a minimum monthly mean of $21-22{ }^{\circ} \mathrm{C}$ in December-January and a maximum monthly mean of $29.5^{\circ} \mathrm{C}$ in April.

\subsection{Rainfall and stemflow measurements}

Incident rainfall $\left(P_{\mathrm{r}}, \mathrm{mm}\right)$ was measured daily with a storage-type rain gauge in an open site about $500 \mathrm{~m}$ away from the stemflow measurement plot (see text below). A tipping-bucket gauge (No. 34T, Ohta Keiki, Tokyo, Japan), interfaced with a datalogger (Hobo Event, Onset Computer, Bourne, MA, USA), was also installed adjacent to the storage-type rain gauge, and the time of tip was recorded to yield the time distribution of rainfall. A discrete rain event was defined as any measureable rainfall that was preceded and followed by at least $6 \mathrm{~h}$ of dry 
conditions (Dunkerley, 2008; Donohue et al., 2012). A total of 857 storm events were measured over the course of study from June 2000 through February 2006. In this study,

rainfall duration $\left(R_{\mathrm{D}}, \mathrm{h}\right)$ was defined as total 10-minute intervals where the tipping-bucket rain gauge detected rainfall occurrence. Event duration $(\mathrm{ED}, \mathrm{h})$ was defined as the total minutes of rainfall including dry periods without rain.

Stemflow volumes (SF, liter) generated by the teak trees were collected using collar type gauges, approximately $1.2 \mathrm{~m}$ above the ground. Among the twenty individual teak trees in a 20 $\mathrm{m} \times 20 \mathrm{~m}$ plot measuring throughfall (Plot A in Tanaka et al., 2015) and SF, we selected nine individuals for SF measurements (Fig. 1) such that dbh of the selected trees covered the full dbh range of the twenty individuals. Height, dbh, and canopy projection area of the nine trees are listed in Table 1. SF was collected in 20 L HDPE vessels and was measured with graduated cylinders on a daily basis; additionally, SF volumes for individuals S2, S10 and S12 were recorded automatically using calibrated tipping-bucket flow meters (No. 34T, Ohta Keiki, Tokyo, Japan) interfaced with dataloggers (KADEC-PLS or KADEC-UP, Kona Systems Inc., Sapporo, Japan). The period of record for trees S2, S10, and S12 were from May 2001 to February 2006, September 2000 to July 2001, and from May 2001 to November 2005, respectively. All SF data were aggregated to a daily total.

$<$ Figure 1 here please >

$<$ Table 1 here please >

\subsection{Acquisition of meteorological data and LAI values}

A 26-m-tall triangular tower, located $20 \mathrm{~m}$ from the SF measurement plot, was used for meteorological measurements. Incident solar radiation above the canopy $\left(R_{\mathrm{s}}, \mathrm{W} \mathrm{m}{ }^{-2}\right)$ was measured from August 2000 at the top of the tower with a silicon pyranometer (LI200X, 
141 Li-Cor, Lincoln, NE, USA). Solar radiation below the canopy $\left(S_{\mathrm{b}}, \mathrm{W} \mathrm{m}^{-2}\right.$, approximately $0.5 \mathrm{~m}$ above ground level) was also measured in the SF plot with pyranometers (MS401, EKO, Tokyo, Japan or CM21, Kipp \& Zonen, Delft, Netherlands) from June 2000 onward. Both sets of radiation data were measured every $5 \mathrm{~s}$ and their 10 min averages were recorded with a datalogger (CR10X, Campbell Scientific, Logan, UT, USA).

Air temperature and relative humidity above the canopy were measured at a height of $26 \mathrm{~m}$ with an aspirated psychrometer (HMP45D, Vaisala, Helsinki, Finland) installed on the tower and recorded every 10 min with a datalogger (SQ1250, Grant Instruments, Cambridge, UK). Wind speed $\left(U, \mathrm{~m} \mathrm{sec}^{-1}\right)$ within the canopy was measured at a height of $17.1 \mathrm{~m}$ as 10 -min averages from July 2002 onward with a cup anemometer (AC750, Makino, Tokyo, Japan) on the tower.

LAI was estimated from seasonal changes in the radiative transmittance, which is the ratio of $S_{\mathrm{b}}$ to $R_{\mathrm{s}}$, through the canopy. Further details on the LAI estimate were provided by Yoshifuji et al. (2011 and 2014). This study assumes that all the investigated trees in the plot showed the same seasonal patterns of LAI as estimated from the radiative transmittance method. From a graphical investigation of the LAI time series (Fig. 2), leafed and leafless canopy states were determined when LAI was greater than or less than $0.5 \mathrm{~m}^{2} \mathrm{~m}^{-2}$, respectively. Because photographs of the teak trees taken at the end of May 2000 showed a fully-leafed canopy, the LAI was assumed to be $2.6 \mathrm{~m}^{2} \mathrm{~m}^{-2}$ from June to August 2000 (Fig. 2), a value equaling the observed LAI on September 1st of the year.

< Figure 2 here please >

\subsection{Stemflow funneling ratio (SFFR)}

Herwitz (1986) defined the stemflow funneling ratio (SFFR) as: 
164

$S F F R=\frac{S F}{P_{r} \pi(d b h / 100 / 2)^{2}}$

where, $\mathrm{SF}$ (liter) is stemflow volume, $P_{\mathrm{r}}(\mathrm{mm})$ is incident rainfall depth equivalent, $\mathrm{dbh}(\mathrm{cm})$ is the diameter at breast height, and $\pi$ is the circular constant. SFFR is a dimensionless number used to indicate the proportion of rainfall magnified by the convergence of branchflow as stemflow at the base of the tree trunk. A SFFR value > 1 indicates that outlying portions of the tree crown contribute to stemflow volume (Levia et al., 2010; Siegert and Levia, 2014). SFFR values were calculated only when $P_{\mathrm{r}}$ exceeded a threshold of $5 \mathrm{~mm}$ day $^{-1}$ to account for times when SF was negligible or non-existent (see Eq. (1)).

\subsection{Data analysis}

Because teak is a deciduous tree species, leaf state can be an important biotic variable for SF as shown for other deciduous tree species in temperate climate (Staelens et al., 2008; Siegert and Levia, 2014). Thus, before performing detailed analyses of the influential variables affecting SFFR, we employed a conventional regression analysis of the observed daily SF against $P_{\mathrm{r}}$ to better understand the effect of foliage on teak SF. After splitting the daily SF data into two groups according to the LAI criterion (see Subsection 2.3), a slope of the linear regression line of SF against $P_{\mathrm{r}}$ was obtained for each canopy state and individual teak tree.

Influential predictors for SFFR were evaluated by boosted regression tree (BRT) analysis. BRT analysis employs both machine learning methods and regression analysis. BRT analysis has some distinct advantages, specifically: the predictor variables can be of any type (numeric, binary, or categorical), it is robust to outliers, it can handle missing data by employing surrogates, and interaction among predictors are modeled automatically (De'ath, 2007; Elith et al., 2008). 
Because the BRT analyses using SFFR as the response variable yielded more valuable insights as to which variables govern stemflow inputs into teak plantations than those based on SF, we opted to use SFFR as our response variable. A total of thirteen variables served as predictors. The first five variables were related to rainfall: rain duration $\left(R_{\mathrm{D}}\right)$, event duration $(\mathrm{ED})$, mean rainfall intensity $\left(I_{\mathrm{n}}, \mathrm{mm} \mathrm{h}^{-1}\right)$, antecedent dry period (ADP, days), and number of rain events per single daily data (ET, times). The next four variables were related to meteorological conditions other than rainfall: solar radiation $\left(R_{\mathrm{s}}\right)$, air temperature $\left(T_{\mathrm{a}},{ }^{\circ} \mathrm{C}\right)$, vapor pressure deficit $(D, \mathrm{kPa})$, and above-canopy wind speed $\left(U, \mathrm{~m} \mathrm{~s}^{-1}\right)$. The last three variables were related to canopy characteristics: canopy height $(\mathrm{H}, \mathrm{m})$, leaf area index (LAI), and canopy state (categorical, leafed/leafless). The values of $R_{\mathrm{s}}, T_{\mathrm{a}}, D$, and $U$ in the dataset were averaged over the rain duration of all events.

We first sought to analyze individual differences in SFFR for teak trees, highlighting details that might be masked in a stand-scale analysis, and then examine stand-scale SFFR dynamics for more general relationships among all trees. In order to understand tree-to-tree variation of SFFR among teak trees, we deployed two BRT analyses for individuals having the maximum and the minimum SFFR (hereafter individual-scale BRT). Because the results of the two BRT analyses showed differential responses of SFFR to LAI between individuals (shown later), the individual-scale BRT was also deployed for the other seven individuals. In these individual-scale BRT analyses, we used SFFR for Period A (Fig. 2) to amplify the meteorological database, although neither $R_{\mathrm{S}}$ nor $U$ were available during this period. The predictor variable $\mathrm{H}$ was not employed in the individual-scale BRT analysis because these variables were quasi-constant throughout the study.

The response variable in our stand-scale BRT analysis was SFFR of all the examined trees for Period B (Fig. 2) when full meteorological variables were available. After application of the $P_{\mathrm{r}}$ 
threshold control $\left(5 \mathrm{~mm} \mathrm{day}^{-1}\right)$, there was a total of 521 daily SF records, which were collected from all the examined individuals (hereafter stand-scale BRT). All twelve variables (listed above) served as predictors in the stand-scale BRT analysis.

BRT analysis was executed by means of R software using the "gbm" package version 2.1 (Ridgeway, 2013) and its extensions developed by Elith et al. (2008). Models were fitted using the gbm.step function and a Gaussian response type, with optimal settings for tree complexity, bag fraction, and learning rate (Table 2). The minimum number of trees was set at 1000. BRT analysis yields the relative influence (RI, \%) of the predictor variables in the model. RI is computed as a result of the number of times that a particular variable was selected for splitting, which was weighed by the squared improvement to the model as a result of each split and averaged over all trees. The RI of each variable is arranged such that the sum adds to 100 , with higher numbers signaling a stronger effect on the response. Partial dependence plots (PDPs) are utilized to gauge individual predictor effects.

$<$ Table 2 here please >

\section{Results}

\subsection{Conventional leafed-leafless state comparisons}

Leafed-leafless comparisons of the slopes of the regression lines of SF on $P_{\mathrm{r}}$ for each individual tree showed that there were distinct differences among some trees (Fig. 3). For more than half of the nine teak trees examined ( $\mathrm{S} 1, \mathrm{~S} 10, \mathrm{~S} 13, \mathrm{~S} 19$, and $\mathrm{S} 20)$, the slope was significantly larger in the leafless state than in the leafed state (Fig. 3). In contrast, for three other trees, there was no significant difference of the slope between canopy states (S2, S15, and S18 in Fig. 3). One tree was even observed to have a significantly larger slope in the leafed state than in the leafless state (S12 in Fig. 3). 


\subsection{Stemflow funneling ratio (SFFR)}

Median SFFR for the overall period varied greatly from tree-to-tree, with a mean median $( \pm$ $\mathrm{SD})$, a maximum median, and a minimum median of $12.8( \pm 8.4), 30.4$, and 2.2 , respectively. The median SFFR for each tree decreased with increasing tree size; the overall median SFFR for teak was negatively correlated with both $\mathrm{dbh}\left(r^{2}=0.45, p<0.05\right)$ and height $\left(r^{2}=0.59, p\right.$ $<0.01)$. The largest SFFR was obtained from a small teak tree (S15, hereafter 'suppressed tree') having a much shorter canopy height $(11.2 \mathrm{~m})$, dbh $(10 \mathrm{~cm})$, and canopy projection area $\left(7 \mathrm{~m}^{2}\right)$ than the corresponding means of the nine individuals (Table 1). The smallest SFFR was obtained from a larger teak tree (S19, $18.5 \mathrm{~m}$ tall, $21 \mathrm{~cm}$ dbh, $14 \mathrm{~m}^{2}$ canopy projection area) with a height, dbh, and canopy projection area larger than the mean (Table 1).

Overall, median SFFR in the leafed state was significantly smaller than that in the leafless state (Fig. 4a), but the tree-to-tree variation was much larger in the leafed state, as can be seen from a larger difference between the minimum and maximum SFFR in the leafed state (Fig. 4a). The median SFFR showed a statistically significant negative correlation with tree height in the leafed state, but, in the leafless state, the median SFFR showed no significant correlation with tree height (Fig. 4b).

$<$ Figure 4 here please >

\subsection{Influential variables of SFFR at the individual tree-scale and the LAI effect}

BRT analysis focusing on individual trees with the largest and the smallest SFFRs showed that there were actually tree-to-tree variations in the array of influential variables governing the SFFR (Fig. 5). Specifically, the most important variable determining the SFFR of S15, with the 
largest SFFR, was $R_{\mathrm{D}}$ followed in descending order of relative influence by $I_{\mathrm{n}}, \mathrm{LAI}, D, \mathrm{ADP}$, ED and $T_{\mathrm{a}}$ (Fig. 5a). In contrast, the most important variable for the SFFR of S19, having the smallest SFFR, was $D$ followed by $I_{\mathrm{n}}, R_{\mathrm{D}}$, and $T_{\mathrm{a}}$ (Fig. $5 \mathrm{~b}$ ). Although the rank of $I_{\mathrm{n}}$ was consistent for both individuals, notable differences in the rankings can be found for $R_{\mathrm{D}}, D$ and LAI (Fig. 5). $R_{\mathrm{D}}$ ranked the first and third highest for S15 and S19, respectively, with $35 \%$ and $15 \%$ of the RI (Fig. 5). In addition, $D$ was predominantly important (54\%) for S19, but less so for S15 where $D$ ranked fourth with $12 \%$ RI (Fig. 5). A biotic variable, LAI, ranked the third with $15 \%$ RI for S15, but, for S19, the RI of LAI was only 1\% (Fig. 5).

$<$ Figure 5 here please >

Although the RI of each predictor differed between the two individuals (Fig. 5), all the variables but LAI generally showed similar effects on the SFFR (Fig. 6). For example, $R_{\mathrm{D}}$ and $I_{\mathrm{n}}$ exerted positive influences on the SFFR of both individuals (Fig. 6). Also, a negative impact of $D$ on the SFFR was found when $D$ ranged from 0.00 to $0.05 \mathrm{kPa}$ for both individuals (Fig. 6). LAI, however, exerted a differential influence on SFFR between individual trees. A PDP of LAI for S15 showed a clear increase in the SFFR with a LAI increase from approximately 1.6 to $2.4 \mathrm{~m}^{2} \mathrm{~m}^{-2}$ (Fig. 6a), but no such increase was observed for S19 (Fig. 6b). As shown in Fig. 7 , the effect of LAI on the SFFR differs considerably between individuals and, for each individual, the PDP curve showed complicated patterns. Nonetheless, several consistent patterns in the PDP curves can be recognized in Fig. 7 as follows: (1) the SFFR decreased with increasing LAI around $0.8 \mathrm{~m}^{2} \mathrm{~m}^{-2}$ for three individuals (S2, S12 and S15); (2) the SFFR increased with increasing LAI around $1.6 \mathrm{~m}^{2} \mathrm{~m}^{-2}$ for three individuals (S12, S15 and S18); (3) the SFFR decreased with increasing LAI around $2.4 \mathrm{~m}^{2} \mathrm{~m}^{-2}$ for three individuals (S2, S12 and S18); and (4) there seems to be no relationship between the SFFR and LAI for three individuals (S1, S13 and S19). As inferred from the results of the conventional regression 
analysis (Fig. 3), these patterns imply that the response of the SFFR to seasonal changes in LAI is not consistent among teak individuals, even though they were planted in the same year and grown in the same plot.

$<$ Figure 6 here please >

$<$ Figure 7 here please >

\subsection{Influential variables of SFFR at the stand-scale}

Stand-scale BRT analyses focusing on all of the individuals, showed that a variety of biotic and abiotic variables intricately affected the SFFR (Figs. 8 and 9). Two variables related to rain characteristics, $R_{\mathrm{D}}$ and $I_{\mathrm{n}}$, were ranked the first and second highest, with RI values of $48 \%$ and $16 \%$, respectively (Fig. 8). Further, both $R_{\mathrm{D}}$ and $I_{\mathrm{n}}$ exerted positive influences on the SFFR (Fig. 9). A biotic variable, H, was the third most important variable with a RI value of $14 \%$ (Fig. 8), exerting a stepwise negative influence on the SFFR (Fig. 9). A meteorological variable, $T_{\mathrm{a}}$, were also important for the SFFR with 7\% RI value (Fig. 8). The SFFR appears to decrease sharply around $23^{\circ} \mathrm{C}$ with increasing $T_{\mathrm{a}}$ (Fig. 9). In addition, ADP had a RI value of $3 \%$, showing a negative impact on the SFFR as long as ADP $<1$ day (Fig. 9). The RI of LAI was unexpectedly small (Fig. 8) and the effect of LAI on SFFR was not straightforward (Fig. 9). There was an intermediate LAI range from approximately 0.8 to $1.6 \mathrm{~m}^{2} \mathrm{~m}^{-2}$ where the SFFR values were slightly depressed (Fig. 9). In addition, LAI had a positive influence on the SFFR when it exceeded approximately $2.6 \mathrm{~m}^{2} \mathrm{~m}^{-2}$ (Fig. 9).

< Figure 8 here please >

< Figure 9 here please >

\section{Discussion}


A number of previous studies on SF of deciduous tree species have shown that SF production in the leafless state was greater than in the leafed state (Helvey and Patric, 1965; Dolman, 1987; Neal et al., 1993; Park et al., 2000; Herbst et al., 2008; Staelens et al., 2008; Siegert and Levia, 2014; Levia and Germer, 2015). The increased exposure of the leafless crowns of deciduous trees to incident rainfall, in the absence of foliage, has been attributed to the augmented SF production in the leafless state (André et al., 2008; Crockford and Richardson, 2000). Increased trunk interception of wind-driven rainfall under more windy conditions within the canopy of the leafless state (as opposed to the leafed state) might also explain the augmented SF of leafless canopies (Helvey and Patric, 1965). The leafed-leafless comparisons of the slopes of regression lines showed that five individuals produced more SF in the leafless state but four other individuals did not (Fig. 3). Fig. 1 provides some insight into this complex result. The four individuals (S2, S12, S15 and S18) showing an identical or a larger slope in the leafed state were partly shaded by crowns of neighboring trees (Fig. 1). In contrast, four individuals (S1, S10, S13 and S20) among the five showing a smaller slope in the leafed state were unshaded by neighboring tree crowns (Fig. 1). This generally aligns with the fact that the SFFR magnitude in the leafed state was negatively correlated with tree height (Fig. 4b).

Because abiotic factors, such as wind speed and direction and rainfall characteristics, are concomitant with changes between canopy states, the results from the regression analysis should be a preliminary indication that canopy state impacts the SF production of teak trees. The varying patterns of the slope between canopy states implies the presence of considerable tree-to-tree variation as to which factors most affect SF production. Furthermore, the tree-to-tree variation in the response of SF generation to canopy state may be caused by the large size of mature teak leaves (discussed later). 


\subsection{Stemflow funneling ratios (SFFR)}

The mean of overall median SFFR for the teak trees studied (12.8) was much higher than unity, indicating that SF was a highly concentrated hydrologic input to trunk bases in our teak plantation. Although the SFFR magnitude is known to show inter- and intrastorm variations, even for specific trees (Levia, 2004; Levia et al., 2010; Van Stan and Levia, 2010), the mean SFFR for teak trees was roughly within the range reported for other tree species in Canada and the United States, with SFFR values of 7.3, 20.6, and 26.3 for oak, maple, and beech trees, respectively (Carlyle-Moses and Price, 2006), and 33.0 and 2.1 for beech and yellow popular trees, respectively (Levia et al., 2010).

Seasonally, the median SFFR in the leafless state was almost double that in the leafed state (Fig. 4a), implying that stand-scale SF production was augmented in the leafless state on the whole, despite the varying responses to canopy state in generating SF on an individual scale (Fig. 3). Interestingly, the median SFFR showed a surprisingly small variation between individuals in the leafless state (Fig. 4a). This implies that the efficiencies of capturing rainfall by leafless teak crowns may potentially be consistent throughout the nine individuals but less uniform under leafed conditions, resulting in larger tree-to-tree variation in the SFFR (Fig. 4a).

\subsection{Influential variables of SFFR at the individual tree-scale and the LAI effect}

The ranks of the most influential factors governing the SFFR differed between individuals as exemplified in Fig. 5. The most influential factors for individuals with the largest and smallest SFFR were $R_{\mathrm{D}}$ and $D$, respectively (Fig. 5). $R_{\mathrm{D}}$ predominantly controlled the SFFR for S15 (suppressed) with a RI value of approximately 35\% and was important also for the large-sized S19 with a RI value of about $15 \%$. The corresponding PDP of $R_{\mathrm{D}}$ for both S15 and S19 showed that a longer rain produced a larger SFFR as long as $R_{\mathrm{D}}$ is less than $2-3 \mathrm{~h}$ (Fig. 6). This result 
implies that water storage capacity of teak bark is temporally variable rather than static (Reid and Lewis, 2009), and that a rain lasting for at least several hours may be necessary for stemflow to infiltrate deep into the bark tissue and to saturate the water storage capacity of the bark (Fig. 6). It is noteworthy that, unlike smooth-barked beech trees having low bark storage capacities (Van Stan and Levia, 2010; Levia and Herwitz, 2005), the bark storage capacity of teak may be large due to its relatively thick bark (Pausus, 2015) and tolerance to ground fire (Goldammer, 2007). The larger RI of $R_{\mathrm{D}}$ for the suppressed individual may reflect the fact that canopy of the suppressed individual was covered by those of neighboring median- and large-sized trees and thus gained only limited access to falling raindrops, especially at the initial stages of a storm. Once the canopies of neighboring trees were saturated, the suppressed tree could start to capture canopy drip from above. This time lag might cause the elevated RI of $R_{\mathrm{D}}$ for the suppressed individual.

During rain, $D$, was of importance in determining the SFFR, especially for the relatively large-sized S19 (Fig. 5). For both S19 and S15, the SFFR was negatively correlated with $D$ for a range between 0 to approximately $0.05 \mathrm{kPa}$ (Fig. 6). Previous studies reported a similar negative impact of $D$ on SF (Staelens et al., 2008; Van Stan et al., 2014). Moreover, a higher evaporation rate from the wetted woody surfaces of trees under drier atmospheric conditions was suggested to be a reason for reduced SF (Van Stan et al., 2014). The ranking difference of $D$ between S15 (fourth) and S19 (first) can be understood after considering that the large-sized S19 would be more prone to the above canopy meteorological environment than the suppressed S15.

Although not as influential as $D, T_{\mathrm{a}}$ did exert an influence over the SFFR with a RI value of $6 \%$ for both the suppressed and the large-sized individuals. While the seasonal variation of $T_{\mathrm{a}}$ was less distinct (Fig. 2) than sites under a temperate climate, a negative influence of $T_{\mathrm{a}}$ on the 
SFFR could be found (Fig. 6), probably due to enhanced evaporation from the wetted woody tree crown. Similar to the individual differences in the RI of $D$, the higher ranking of $T_{\mathrm{a}}$, and the slightly larger RI of $T_{\mathrm{a}}$ for the large-sized tree than the suppressed tree can be attributed to a more exposed condition of the large-sized individual to the ambient atmosphere.

For both individuals, $I_{\mathrm{n}}$ was of the second highest importance in determining the SFFR (Fig. 5), exerting positive influences as long as $I_{\mathrm{n}}$ was less than approximately $20 \mathrm{~mm} \mathrm{~h}^{-1}$ (Fig. 6). Carlyle-Moses and Price (2006) suggested that strong rain intensity and resultant high water flow along a trunk and branches triggered stemflow detachment from the tree, resulting in the SFFR reduction for red oak, sugar maple and American beech trees. Similar SF detachments were suggested to occur for European beech (Staelens et al., 2008) and tropical tree species (Herwitz, 1987). At 5-minute intrastorm intervals, the SFFR amounts were also reduced for yellow popular and American beech trees as rainfall intensity increased (Levia et al., 2010). Our results for teak trees, however, showed that there was little indication of the detachment of stemflow for rain $<20 \mathrm{~mm} \mathrm{~h}^{-1}$. This observation may be attributed to the fact that teak trees have a straight bole (Pandy and Brown, 2000) and a vertically- and narrowly-furrowed bark texture, better channeling the water flow running downward on the trunk. Some similarities with rainfall intensity have been found for some large beech trees during the leafed period at the event scale under certain conditions (Van Stan et al., 2014). It is important to note that the temporal scale of analysis (5-minute, hourly, storm) will change the relationship between stemflow yield and rainfall intensity (Dunkereley, 2014; Levia and Germer, 2015). As such, the temporal scale of SF and SFFR should always be taken into account since event scale data (and coarser) masks important intrastorm dynamics that affect SF yield and the SFFR at different times within particular events that result in different relationships between $I_{\mathrm{n}}, \mathrm{SF}$, and the SFFR. 
LAI had the third and the eighth highest importance for the suppressed (S15) and the large-sized (S19) trees, respectively (Fig. 5). The LAI effect on the SFFR was intricate and differs considerably among individual teak trees (Fig. 7). Our result was different from some previous work that found that the SFFR of deciduous forests was reduced in the leafed state (as reviewed by Levia and Frost, 2003). Siegert and Levia (2014) also showed SFFR reductions in the leafed state. Morphologically, the most prominent characteristic of teak may be its large-sized mature leaves (Grace et al., 1982; Jarvis and McNaughton, 1986; Pandy and Brown, 2000). The leaf is typically $30-60 \mathrm{~cm}$ in length (Pandy and Brown, 2000) and is comparable or even larger than stem diameters of the teak trees examined in this study $(\sim 20 \mathrm{~cm}$ in this study, Table 1). Such large-sized leaves probably produced both a rain-shadow effect and rain-concentrated spots on specific branches and trunks in the leafed state. Therefore, we hypothesized that an individual tree entraining water from concentrated sources can effectively generate SF even in the leafed state. In case of our study, the three individuals showing larger SFFRs with increasing LAI (S12, S15 and S18) may be categorized into this group.

As mentioned in Section 3.3, three individuals showed a SFFR decline with increasing LAI at around $1.0 \mathrm{~m}^{2} \mathrm{~m}^{-2}$ (Fig. 7). Because there were a limited number of storms in the leaf senescence phase at our site (Tanaka et al., 2015), the SFFR declines can be considered to occur mainly in the leafing phase when young smaller-sized (but normal-sized for other deciduous tree species) leaves appear. We consider that the reduction in SFFR during the leafing phase of teak trees may be caused by the same mechanism that was reported for other deciduous tree species (e.g., the leaf-shading effect of branches and trunks) (Crockford and Richardson, 2000). Such a possible leaf-size effect on SF was also inferred by Aboal et al. (1999). In summary, the spatially heterogeneous flow paths inside the teak canopy may account for the observed tree-to-tree variation in SF yield in the leafed state. 


\subsection{Influential variables of SFFR at the stand-scale}

By adding a biotic factor, $\mathrm{H}$, and abiotic factors, $R_{\mathrm{s}}$ and $U$, as predictor variables in the BRT analysis, we found that $\mathrm{H}$ was of the third highest importance (Fig. 8), exerting a negative influence on the SFFR (Fig. 9). The negative influence of $\mathrm{H}$ on the SFFR was congruent with the findings in Section 3.2 and Fig. 4b. An intuitive expectation that a taller individual can produce larger SF and thus a larger SFFR was not found for these teak trees. The unexpected result may primarily be caused by a larger bark storage capacity of a taller teak trees. In addition, some other factors that were important in the individual tree scale BRT analyses (e.g., $R_{\mathrm{D}}, I_{\mathrm{n}}, T_{\mathrm{a}}$ and LAI) were also important at the stand scale.

ADP ranked as the fifth most important predictor in the stand-scale BRT analysis (Fig. 8). As reported previously for other tree species (André et al., 2008; Siegert and Levia, 2014), our BRT analysis for teak trees showed that a storm with a longer ADP produced a lower SFFR. Our analysis additionally permitted us to estimate a required drying time in which water stored in the bark could be evaporated. The drying time was approximated to be one day (see PDP for ADP in Fig. 9).

In the stand-scale BRT analyses, the PDPs (Fig. 9) can be taken as a composite showing the effects of each factor on the SFFR. Hence, the effects of $R_{\mathrm{D}}, I_{\mathrm{n}}, T_{\mathrm{a}}$ and the ADP on the SFFR in the stand-scale BRT analysis (Fig. 9) were almost the same as corresponding PDPs in Fig. 6 a and 6b. Unlike the PDP for $T_{\mathrm{a}}$ (Fig. 6a), Fig. 9 showed a sharper decline in the SFFR at around $23^{\circ} \mathrm{C}$, but this apparent sharp decline was caused partly by clumping of $T_{\mathrm{a}}$ data around $23-24^{\circ} \mathrm{C}$ (see smooth SFFR decline in the corresponding magnification in Fig. 9). In addition, sharp annual decreases in $T_{\mathrm{a}}$ in the early wet season (Fig. 2) could partly explain the sharp SFFR drop in Fig. 9. At our site, storms with high $T_{\mathrm{a}}$ mainly occurred in the early wet season (not 
shown), when SF production could be lowered by relatively high $T_{\mathrm{a}}$ during both rainfall and the ADP. Our BRT analysis included the ADP as a predictor variable, but not evaporation during the ADP (André et al., 2008). As such, the apparent steep SFFR decrease (Fig. 9) may be reinforced by a negative impact of evaporation in the dry period between rain events. In fact, we are just beginning to better understand the role of pre-event canopy storage on precipitation partitioning (Allen et al., 2014).

The individual-scale BRT analyses showed considerable tree-to-tree variation in the response of the SFFR to LAI and, for each individual, the PDP showed an intricate pattern (Fig. 7). The stand-scale BRT analysis also showed a complex pattern (Fig. 9). As discussed in Section 4.3, the intermediate LAI range (approximately 0.8 and. $1.6 \mathrm{~m}^{2} \mathrm{~m}^{-2}$ ) corresponded to the leafing phase of teak trees. Therefore, the SFFR reduction in the intermediate LAI range might be caused by a shading effect by the smaller-sized young teak leaves. Interestingly, the ratio of throughfall to gross rainfall was maximized at $93 \%$ in this leafing phase at this teak plantation (Tanaka et al., 2015). Part of the reduced SF in the leafing phase may counterbalance the excess of throughfall during this phase.

By analyzing the monthly median SFFR for beech and popular trees, Siegert and Levia (2014) reported that the SFFR was reduced immediately after the leaf emergence on the canopy and stayed at a lowered SFFR level throughout the leafed phase. The teak trees in our study also exhibited a SFFR reduction following leaf emergence. However, unlike beech and popular trees, the teak SFFR, on a stand-scale, increased in the fully-leafed phase when LAI $>1.6 \mathrm{~m}^{2}$ $\mathrm{m}^{-2}$ (Fig. 9). It should be noted that the monthly median SFFR reported in Siegert and Levia (2014) might also be influenced by seasonal changes in rainfall and meteorological factors, whereas our BRT analysis focused solely on the LAI effect. However, as Siegert and Levia (2014) suggested, our result highlighted the importance of separating the leafed-leafless states 
into finer canopy phenophases for better understanding and modeling of SF of deciduous tree species.

\section{Conclusion}

Our results indicate that the SFFR values from teak trees are likely to affect soil moisture in the near-trunk zone, possibly engendering a hot spot. This is the first known study to delineate stemflow for a deciduous tree species in relation to daily LAI data. Because LAI exerted complicated influences on SFF of each tree (Fig. 7), a simple leafed-leafless comparison of stemflow may be insufficient for better understanding stemflow generation of teak trees. The BRT analyses allowed us to rank the influential factors governing SFFR of teak trees and to provide mechanistic explanations for the SFFR at both individual tree and stand scales. As such, these results are of use to future work on stemflow modelling. Although this study focused on teak trees, our physically-based mechanistic explanations of stemflow production could apply to other even-aged deciduous forests and monospecific plantations. .

\section{Acknowledgements}

This work was funded by the Core Research for Evolutional Science and Technology (CREST) program of the Japan Science and Technology (JST) Agency, the Ministry of Education, Culture, Sports, Science and Technology in Japan through a project titled "Program for risk information on climate change”, and Grant-in-Aid for Scientific Research (\#23405028, \#24405031, \#23780161, \#24310018, \#22780139). We are grateful to Mika Kawamoto for setting-up the stemflow collectors and also to graduate students from the Faculty of Forestry, Kasetsart University for their assistance in the field. We would like to thank Suwan Pakrat and Srinuan Tunjai for their daily measurements of rainfall and stemflow. We further thank the two anonymous reviewers as well as the Editors for their thoughtful comments which greatly 
improved our manuscript. Finally, we also would like to acknowledge the Forestry Industrial Organization (FIO) in Thailand for their kind consideration of our research.

\section{References}

Aboal, J.R., Morales, D., Hernández, M., Jiménez, M.S., 1999. The measurement and modelling of the variation of stemflow in a laurel forest in Tenerife, Canary Islands. J. Hydrol. 221, 161-175.

Allen, S.T., Brooks, J.R., Keim, R.F., Bond, B.J., McDonnell, J.J., 2014. The role of pre-event canopy storage in throughfall and stemflow by using isotopic tracers. Ecohydrology 7 , $858-868$.

André, F., Jonard, M., Ponette, Q., 2008. Influence of species and rain event characteristics on stemflow volume in a temperate mixed oak - beech stand. Hydrol. Process. 22, $4455-4466$

Brown, J.H., Barker A.C., 1970. An analysis of throughfall and stemflow in mixed oak stands, Water Resour. Res. 6, 316 -323.

Buvaneswaran, C., George, M., Mohan, S., 2003. Distribution of rainfall under teak plantation. Indian Forester 129, 571-577.

Carlyle-Moses, D.E., Price, A.G., 2006. Growing-season stemflow production within a deciduous forest of southern Ontario. Hydrol. Process. 20, 3651-3663.

Carlyle-Moses, D.E., Schooling, J.T., 2015. Tree traits and meteorological factors influencing the initiation and rate of stemflow from isolated deciduous trees. Hydrol. Process. 29, 
4083-4099.

512 Castillo, E.T., 1986. Hydrologic response of different existing plantation in the Agusan River Basin. From http://scinet.dost.gov.ph (accessed on 06.18.16).

Chang, S-C., Matzner E., 2000. The effect of beech stemflow on spatial patterns of soil solution chemistry and seepage fluxes in a mixed beech/oak stand. Hydrol. Process. 14, $135-144$

Charoensuk, S., Jirasaktaveckul, W., Onessa, S., 1989. Rainfall intercepted by teak plantation, in: Nalanpoon, A., Thitirojanawat, P., Tippharot, P. (Eds.), Abstract of Research Works in Watershed Management in Thailand. Royal Forest Department, Bankok, Thailand, pp. 39.

Crockford, R., Richardson, D., 2000. Partitioning of rainfall into throughfall, stemflow and interception: effect of forest type, ground cover and climate. Hydrol. Process. 14, $2903-2920$

Dabral, B.G., Subba Rao, B.K., 1968. Interception studies in chir and teak plantations-new forest. Indian Forester 94, 541-551.

De'ath, G., 2007. Boosted trees for ecological modeling and prediction. Ecology 88, 243-251.

Dolman, A.J., 1987. Summer and winter rainfall interception in an oak forest. Predictions with an analytical and a numerical simulation model. J. Hydrol. 90, 1-9.

Donohue, R.J., Roderick, M.L., McVicar, T.R., 2012. Roots, storms and soil pores: Incorporating key ecohydrological processes into Budyko's hydrological model. J. Hydrol. 436-437, 35-50. 
Dunkerley, D., 2008. Identifying individual rain events from pluviograph records: A review with analysis of data from an Australian dryland site. Hydrol. Process. 22, 5024-5036.

Dunkerley, D., 2014. Stemflow on the woody parts of plants: Dependence on rainfall intensity and event profile from laboratory simulations. Hydrol. Process. 28, 5469-5482.

Durocher, M.G., 1990. Monitoring spatial variability of forest interception. Hydrol. Process. 4, $215-229$.

Elith, J., Leathwick, J.R., Hastie, T., 2008. A working guide to boosted regression trees. J. Anim. Ecol. 77, 802-813.

Germer, S., 2013. Development of near-surface perched water tables during natural and artificial stemflow generation by babassu palms. J. Hydrol. 507, 262-272.

Gersper, P.L., Holowaychuk, N., 1971. Some effects of stem flow from forest canopy trees on chemical properties of soils. Ecology 52, 691-702.

Goldammer, J.G., 2007. History of equatorial vegetation fires and fire research in Southeast Asia before the 1997-98 episode: A reconstruction of creeping environmental changes. Mitig. Adapt. Strat. Glob. Change 12, 13-32.

Gönczöl, J., Révay, A., 2004. Fungal spores in rainwater: Stemflow, throughfall and gutter conidial assemblages. Fungal Diversity 16, 67-86.

Grace, J., Okali, D.U.U., Fasehun, F.E., 1982. Stomatal conductance of two tropical trees during the wet season in Nigeria. J. Appl. Ecol. 19, 659-670.

Helvey, J.D., Patric, J.H., 1965. Canopy and litter interception of rainfall by hardwoods of eastern United States. Water Resour. Res. 1, 193-206. 
Herbst, M., Rosier, P.T.W., McNeil, D.D., Harding, R.J., Gowing, D.J., 2008. Seasonal variability of interception evaporation from the canopy of a mixed deciduous forest. Agric. For. Meteorol. 148, 1655-1667.

Herwitz, S.R., 1986. Infiltration-excess caused by stemflow in a cyclone-prone tropical rainforest. Earth Surf. Process. Landforms 11, 401-412.

Herwitz, S.R., 1987. Raindrop impact and water flow on the vegetative surfaces of trees and the effects on stemflow and throughfall generation. Earth Surf. Process. Landforms 12, $425-432$.

Iida, S., Shimizu, A., Kabeya, N., Nobuhiro, T., Tamai, K., Shimizu, T., 2010. Tree-to-tree variations in stemflow amounts of Japanese cedar in Tsukuba experimental watershed [in Japanese]. Kanto J. For. Res. 61, 207- 210.

Jarvis, P.G., McNaughton, K.G., 1986. Stomatal control of transpiration: scaling up from leaf to region. Adv. Ecol. Res. 15, 1-49.

Johnson, M.S., Lehmann, J., 2006. Double-funneling of trees: stemflow and root-induced preferential flow. Ecoscience 13, 324-333.

Kollert, W., Cherubini, L., 2012. Teak Resources and Market Assessment 2010. FAO Planted Forests and Trees Working Paper FP/47/E, Rome, Italy. From http://www.fao.org/forestry/plantedforests/67508@170537/en/ (accessed on 06.18.16)

Krishnapillay, B., 2000. Silviculture and management of teak plantations. Unasylva 201, $14-21$.

Levia, D.F., 2004. Differential winter stemflow generation under contrasting storm conditions in a southern New England broad-leaved deciduous forest. Hydrol. Process. 18, 
Levia, D.F., Frost, E.E., 2003. A review and evaluation of stemflow literature in the hydrologic and biogeochemical cycles of forested and agricultural ecosystems. J. Hydrol. 274, $1-29$.

Levia, D.F., Germer, S., 2015. A review of stemflow generation dynamics and stemflow-environment interactions in forests and shrublands. Rev. Geophys. 53, $673-714$.

Levia, D.F., Herwitz, S.R., 2005. Interspecific variation of bark water storage capacity of three deciduous tree species in relation to stemflow yield and solute flux to forest soils. Catena 64, 117-137.

Levia, D.F., Michalzik, B., Näthe, K., Bischoff, S., Richter, S., Legates, D.R., 2015. Differential stemflow yield from European beech saplings: the role of individual canopy structure metrics. Hydrol. Process. 29, 43-51.

Levia, D.F., Van Stan, J.T., Mage, S.M., Kelley-Hauske, P.W., 2010. Temporal variability of stemflow volume in a beech-yellow poplar forest in relation to tree species and size. J. Hydrol. 380, 112-120.

Liang, W.-L., Kosugi, K., Mizuyama, T., 2007. Heterogeneous soil water dynamics around a tree growing on a steep hillslope. Vadose Zone J. 6, 879-889.

Liang, W.-L., Kosugi, K., Mizuyama, T., 2011. Soil water dynamics around a tree on a hillslope with or without rainwater supplied by stemflow. Water Resour. Res. 47, W02541, doi:10.1029/2010WR009856. 
McClain, M.E., Boyer, E.W., Dent, C.L., Gergel, S.E., Grimm, N.B., Groffman, P.M., Hart, S.C., Harvey, J.W., Johnston, C.A., Mayorga, E., McDowell, W.H., Pinay, G., 2003. Biogeochemical hot spots and hot moments at the interface of terrestrial and aquatic ecosystems. Ecosystems 6, 301-312.

Neal, C., Robson, A.J., Bhardwaj, C.L., Conway, T., Jeffery, H.A., Neal, M., Ryland, G.P., Smith, C.J., Walls, J., 1993. Relationships between precipitation, stemflow and throughfall for a lowland beech plantation, Black Wood, Hampshire, southern England: findings on interception at a forest edge and the effects of storm damage. J. Hydrol. 146, $221-233$.

Okali, D.U.U., 1980. Estimating water use by tropical forests: an example from a plantation teal forest, in: Furtado, J.I. (Ed), Tropical Ecology and Development, Proceedings of the Vth International Symposium of Tropical Ecology, International Society of Tropical Ecology, Department of Botany, Banaras Hindu University, Varanasi, India, pp. $581-591$.

Pandy, D., Brown, C., 2000. Teak: a global overview. Unasylva 201, 3-13.

Park, H., Hattori, S., Kang, H., 2000. Seasonal and inter-plot variations of stemflow, throughfall and interception loss in two deciduous broad-leaved forests. J. Jap. Soc. Hydrol. Water Resour. 13, 17-30.

Pausus, J.G., 2015. Bark thickness and fire regime. Funct. Ecol. 29, 315-327.

Reid, L.M., Lewis, J., 2009. Rates, timing, and mechanisms of rainfall interception loss in a coastal redwood forest. J. Hydrol. 375, 459-470.

Ridgeway, G., 2013. gbm: Generalized boosted regression models. R package version 2.1. 
Siegert, C.M., Levia, D.F., 2014. Seasonal and meteorological effects on differential stemflow funneling ratios for two deciduous tree species. J. Hydrol. 519, 446-454.

Sridhar, K.R., Karamchand, K.S., 2009. Diversity of water-borne fungi in stemflow and throughfall of tree canopies in India. Sydowia 61, 327-344.

Srinivasan, M., Mani K, A., Kiruba, M., 2012. Nutrient gains by stem flow, through fall and rainfall in teak ecosystem, Proceedings of 17th International Forestry and Environment Symposium 2012, Department of Forestry and Environmental Science, University of Sri Jayewardenepura, Sri Lanka, pp. 64.

Staelens, J., Herbst, M., Hölscher, D., Schrijver, A.De., 2011. Seasonality of hydrological and biogeochemical fluxes, in: Levia, D.F., Carlyle-Moses, D.E., Tanaka, T. (Eds.), Forest Hydrology and Biogeochemistry: Synthesis of Past Research and Future Directions. Springer-Verlag, Heidelberg, Germany, pp. 521-539.

Staelens, J., Schrijver, A.De., Verheyen, K., Verhoest, N.E.C., 2008. Rainfall partitioning into throughfall, stemflow, and interception within a single beech (Fagus sylvatica L.) canopy: influence of foliation, rain event characteristics, and meteorology. Hydrol. Process. 22, 33-45.

Tanaka, N., Levia, D., Igarashi, Y., Nanko, K., Yoshifuji, N., Tanaka, K., Tantasirin, C., Suzuki, M., Kumagai, T., 2015. Throughfall under a teak plantation in Thailand: a multifactorial analysis on the effects of canopy phenology and meteorological conditions. Int. J. Biometeorol. 59, 1145-1156.

Tanaka, T., 2011. Effects of the canopy hydrologic flux on groundwater, in: Levia, D.F., Carlyle-Moses, D.E., Tanaka, T. (Eds.), Forest Hydrology and Biogeochemistry: 
Van Stan, J.T., Levia, D.F., 2010. Inter- and intraspecific variation of stemflow production from Fagus grandifolia Ehrh. (American beech) and Liriodendron tulipifera L. (yellow poplar) in relation to bark microrelief in the eastern United States. Ecohydrology 3, $11-19$.

Van Stan, J.T., Siegert, C.M., Levia, D.F., Scheick, C.E., 2011. Effects of wind-driven rainfall on stemflow generation between codominant tree species with differing crown characteristics. Agric. For. Meteorol. 151, 1277-1286.

Van Stan, J.T., Van Stan, J.H., Levia, D.F., 2014. Meteorological influences on stemflow generation across diameter size classes of two morphologically distinct deciduous species. Int. J. Biometeorol. 58, 2059-2069.

Yoshifuji, N., Igarashi, Y., Tanaka, N., Tanaka, K., Sato, T., Tantasirin, C., Suzuki, M., 2014. Inter-annual variation in the response of leaf-out onset to soil moisture increase in a teak plantation in northern Thailand. Int. J. Biometeorol. 58, 2025-2029.

Yoshifuji, N., Komatsu, H., Kumagai, T., Tanaka, N., Tantasirin, C., Suzuki, M., 2011. Interannual variation in transpiration onset and its predictive indicator for a tropical deciduous forest in northern Thailand based on 8-year sap-flow records. Ecohydrology 4, $225-235$. 
Table 1

664

665 Tree height $(\mathrm{H})$, diameter at breast height (dbh, $1.37 \mathrm{~m})$ and canopy projection area of nine experimental teak trees in Mae Mo district, Lampang province, northern Thailand.

667

668

\begin{tabular}{llll}
\hline Tree ID & Height $(\mathrm{m})$ & dbh $(\mathrm{cm})$ & Canopy projection area $\left(\mathrm{m}^{2}\right)$ \\
\hline S1 & 16.5 & 17 & 14 \\
S2 & 16.5 & 24 & 16 \\
S10 & 19.6 & 22 & 19 \\
S12 & 15.6 & 19 & 14 \\
S13 & 16.4 & 21 & 16 \\
S15 & 11.2 & 10 & 7 \\
S18 & 17.4 & 16 & 6 \\
S19 & 18.5 & 21 & 14 \\
S20 & 16.8 & 19 & 7 \\
\hline Mean & 16.5 & 19 & 13 \\
\hline
\end{tabular}


Table 2

671

672 List of optimal parameters used in the BRT analyses.

673

\begin{tabular}{lccc}
\multicolumn{1}{c}{$\begin{array}{l}1 \\
\text { Analysis }\end{array}$} & Tree complexity & Bag fraction & Learning rate \\
\hline Stand-scale & 10 & 0.7 & 0.0016 \\
Individual-scale S1 & 10 & 0.8 & 0.0016 \\
Individual-scale S2 & 9 & 0.7 & 0.0010 \\
Individual-scale S12 & 6 & 0.6 & 0.0016 \\
Individual-scale S13 & 5 & 0.8 & 0.0013 \\
Individual-scale S15 & 10 & & 0.0025 \\
Individual-scale S18 & & 0.8 & 0.0025 \\
Individual-scale S19 & 8 & 0.8 & 0.0001 \\
\hline
\end{tabular}

674

$675{ }^{1}$ Please note that the individual-scale BRT analyses are not listed for trees S10 and S20 since

676 the BRT analysis could not be resolved due insufficient number of SFFR data for each tree. 


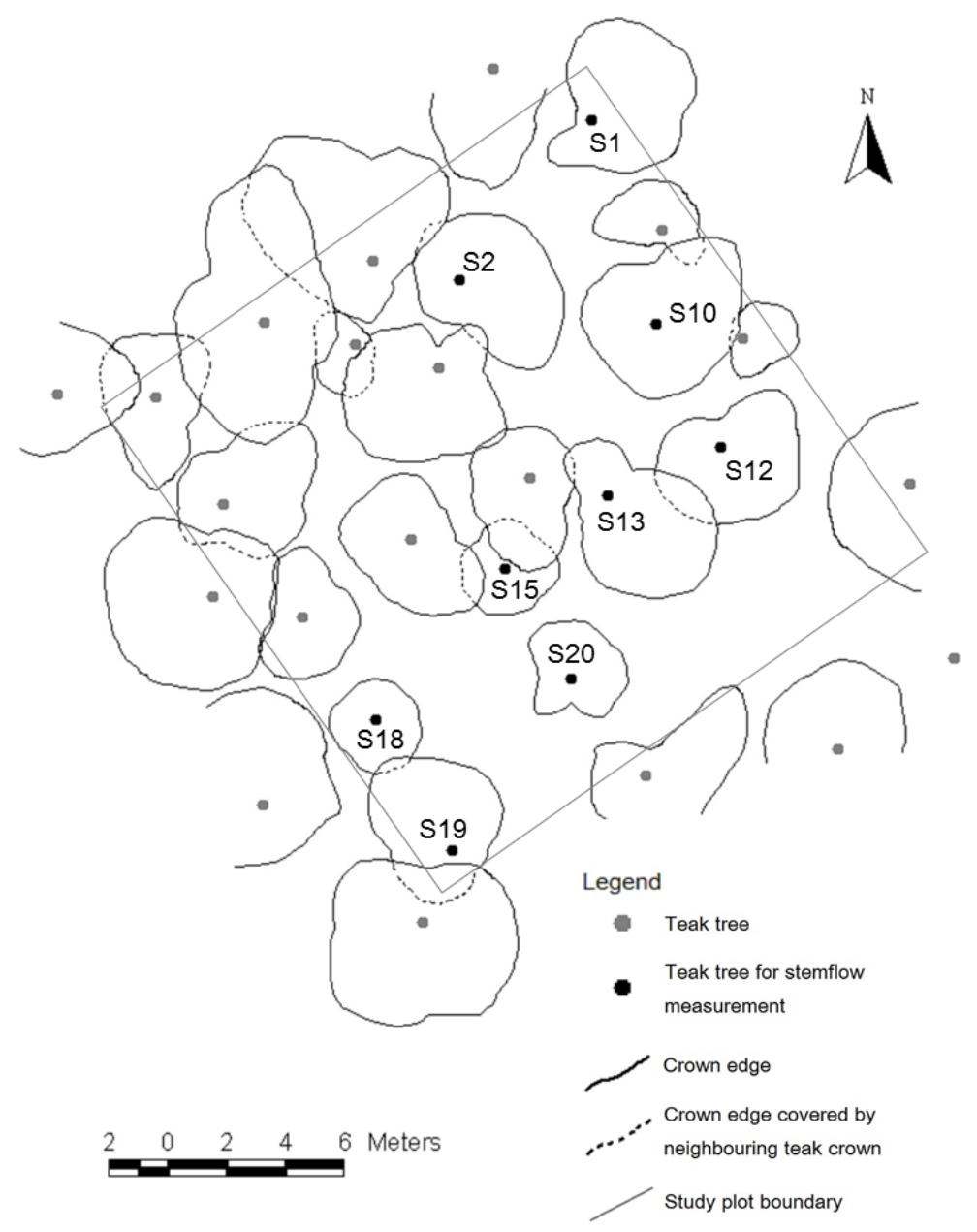

2 Figure 1

3 Canopy projection map of teak trees located in and near the $20 \mathrm{~m} \times 20 \mathrm{~m}$ plot of Mae Mo plantation.

4 The stem position of the nine teak trees investigated in this study is indicated by a black solid circle with 5 each tree ID.

6 


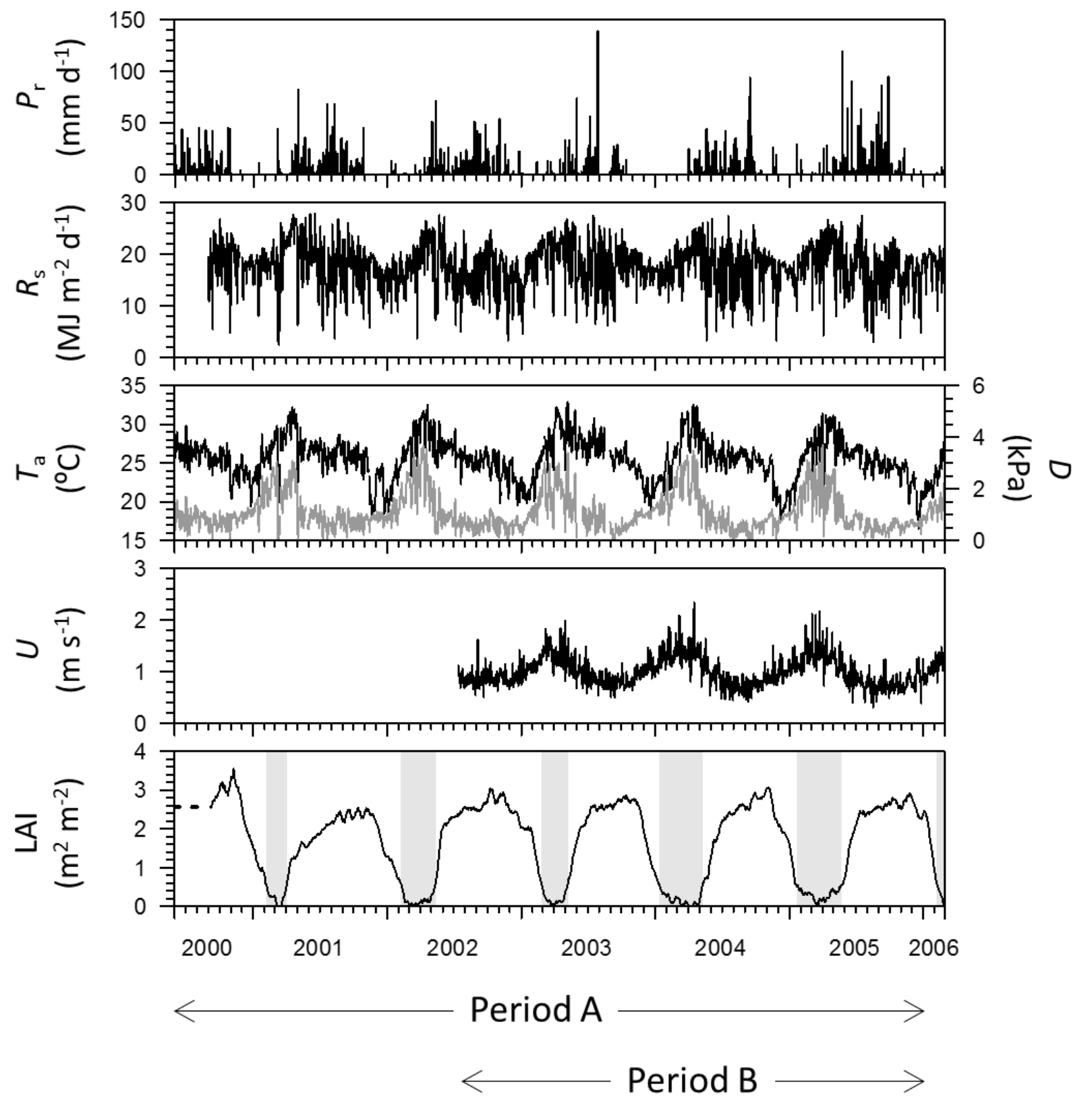

Figure 2

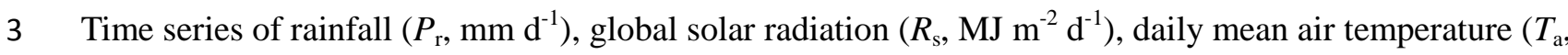

$4{ }^{\circ} \mathrm{C}$, black line in the mid panel), daily mean vapor pressure deficit ( $D, \mathrm{kPa}$, gray line in the mid panel),

5 daily mean wind speed $\left(U, \mathrm{~m} \mathrm{~s}^{-1}\right)$ and leaf area index (LAI, $\left.\mathrm{m}^{2} \mathrm{~m}^{-2}\right)$. Gray-colored bars in the bottom

6 panel indicates leafless periods where $\mathrm{LAI}<0.5 \mathrm{~m}^{2} \mathrm{~m}^{-2}$, while white indicates leafed periods. 


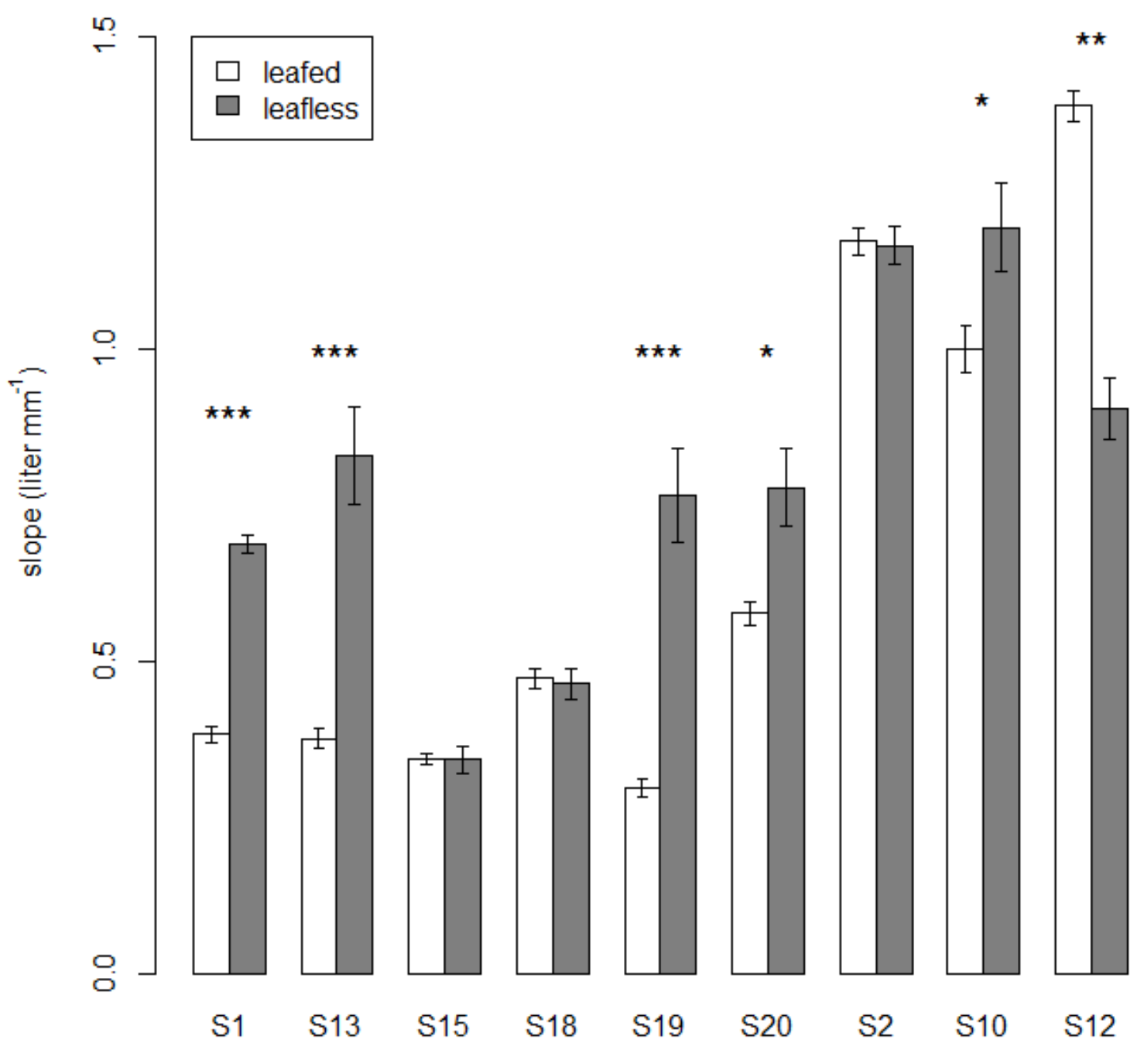

2 Figure 3

3 Leafed-leafless comparisons of slopes of the regression lines of stemflow on rainfall for each teak tree.

4 Error bars indicate standard errors of the slope. Significance levels of the leafed-leafless difference in

5 the slope are also indicated from the analyses of covariance $(* * * p<0.001, * * p<0.01, * p<0.05)$.

6 


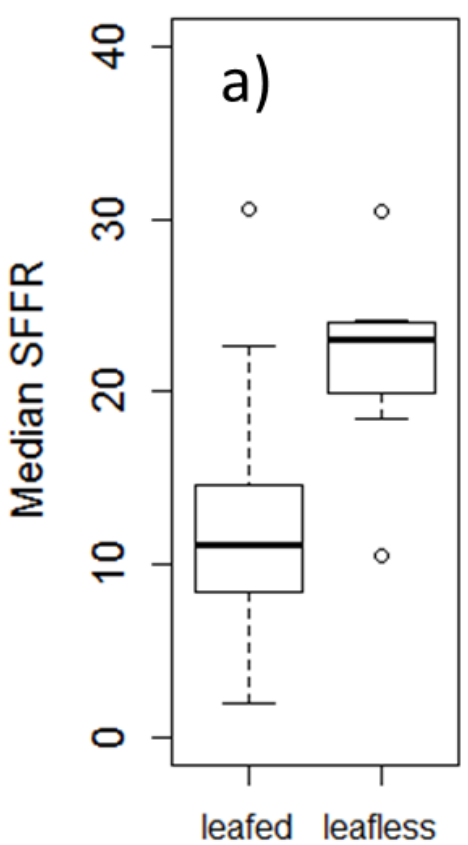

Canopy state

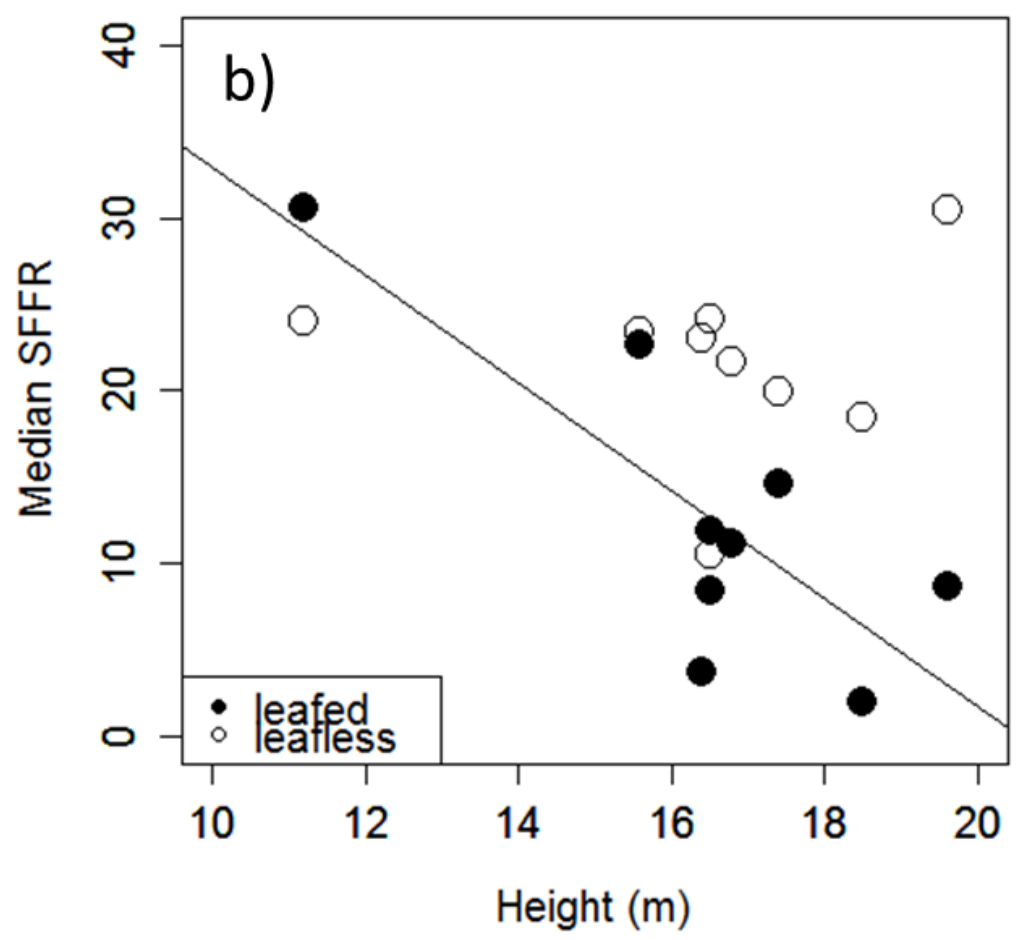
height was found in the leafed state only (solid line, $r^{2}=0.59, p<0.01$ ). 

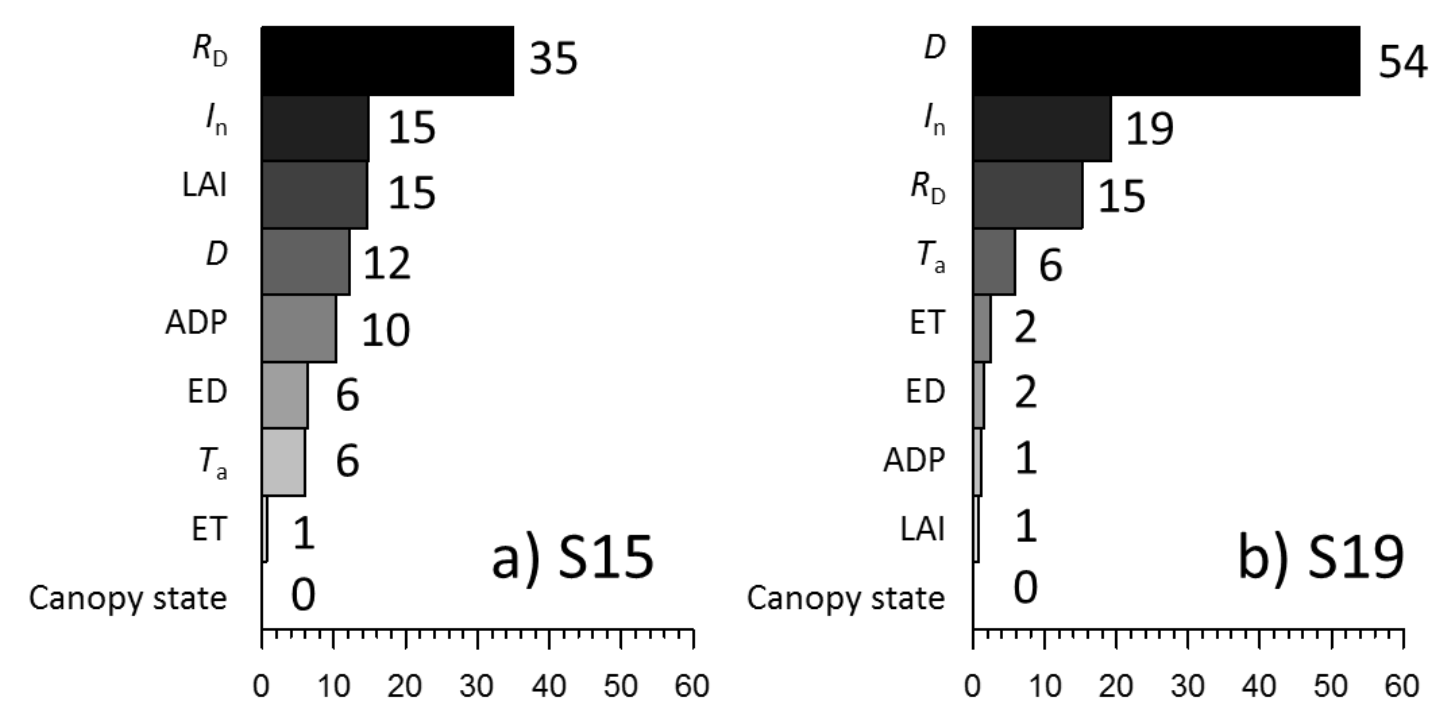

\section{Relative influence (\%)}

2 Figure 5

3 Relative predictor variable influence for stemflow funneling ratio of (a) S15 and (b) S19, having the

4 largest and the smallest SFFR, respectively, among the individual teak trees. Abbreviations in the figure

5 denote rain duration $\left(R_{\mathrm{D}}\right)$, mean rainfall intensity $\left(I_{\mathrm{n}}\right)$, leaf area index (LAI), vapor pressure deficit $(D)$,

6 antecedent dry period (ADP), rain event duration (ED), air temperature $\left(T_{\mathrm{a}}\right)$, and number of rain event

$7 \quad(\mathrm{ET})$

8 


\section{a) S15}
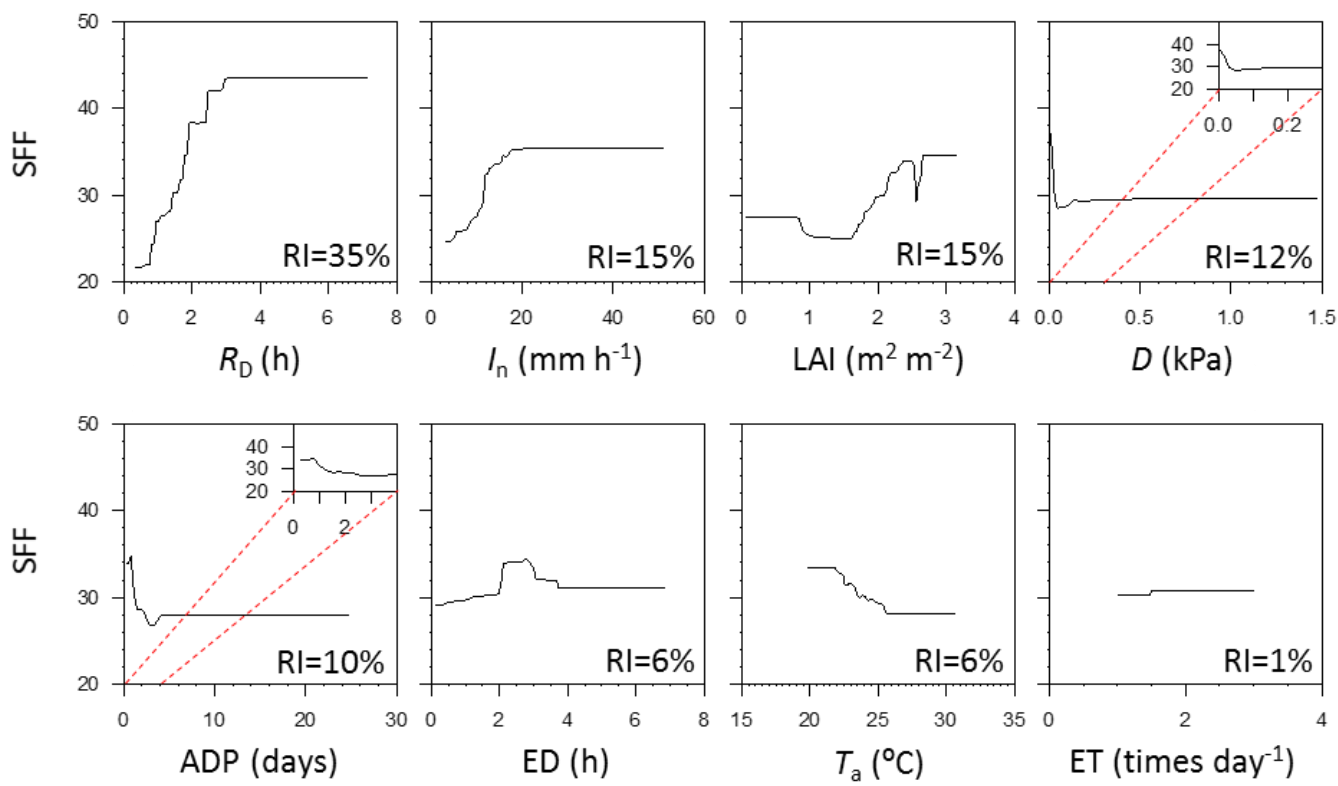

\section{b) S19}
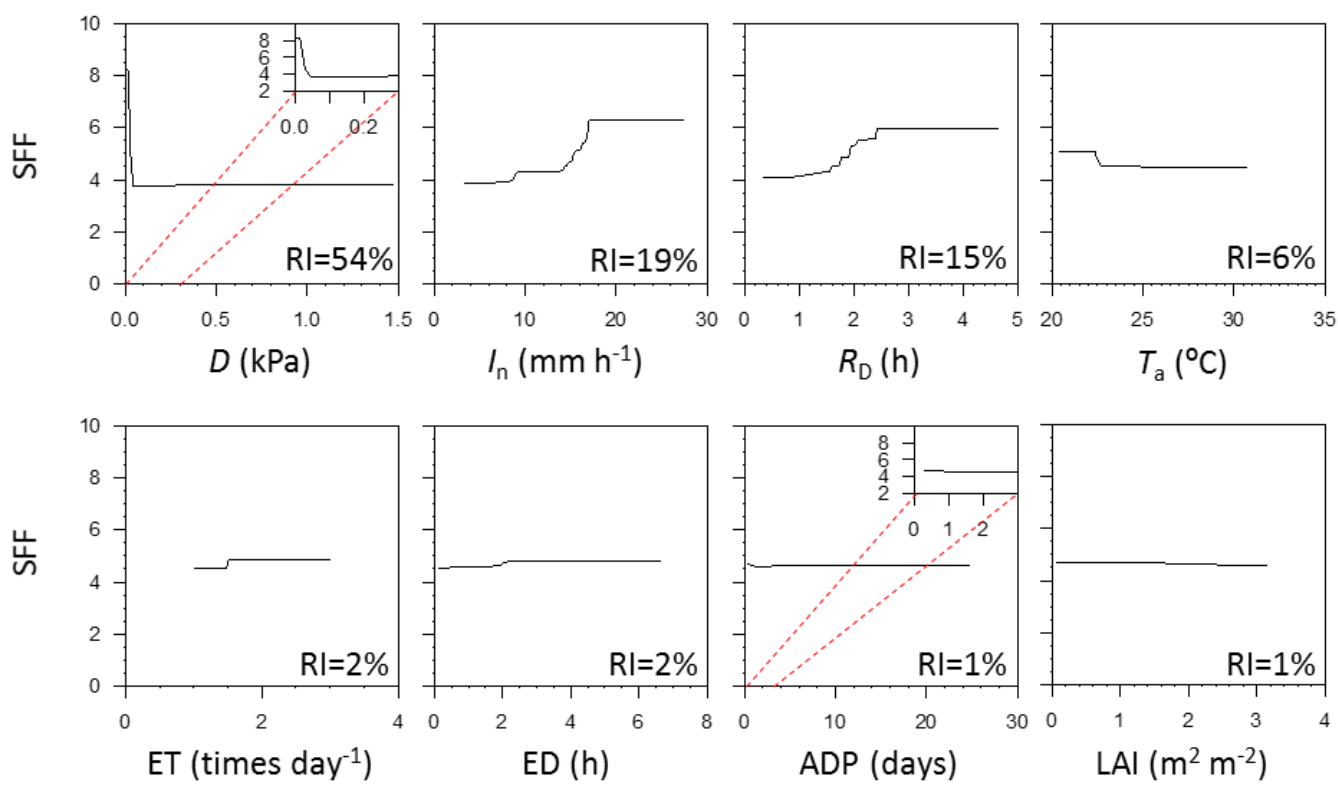

2 Figure 6

3 Partial dependence plots of predictor variables with a higher rank than 8th and their effect on stemflow

4 funneling ratio of (a) S15 and (b) S19, having the largest and the smallest SFFR, respectively, among the

5 individual teak trees. Abbreviations in this figure are the same as in Fig. 5. 


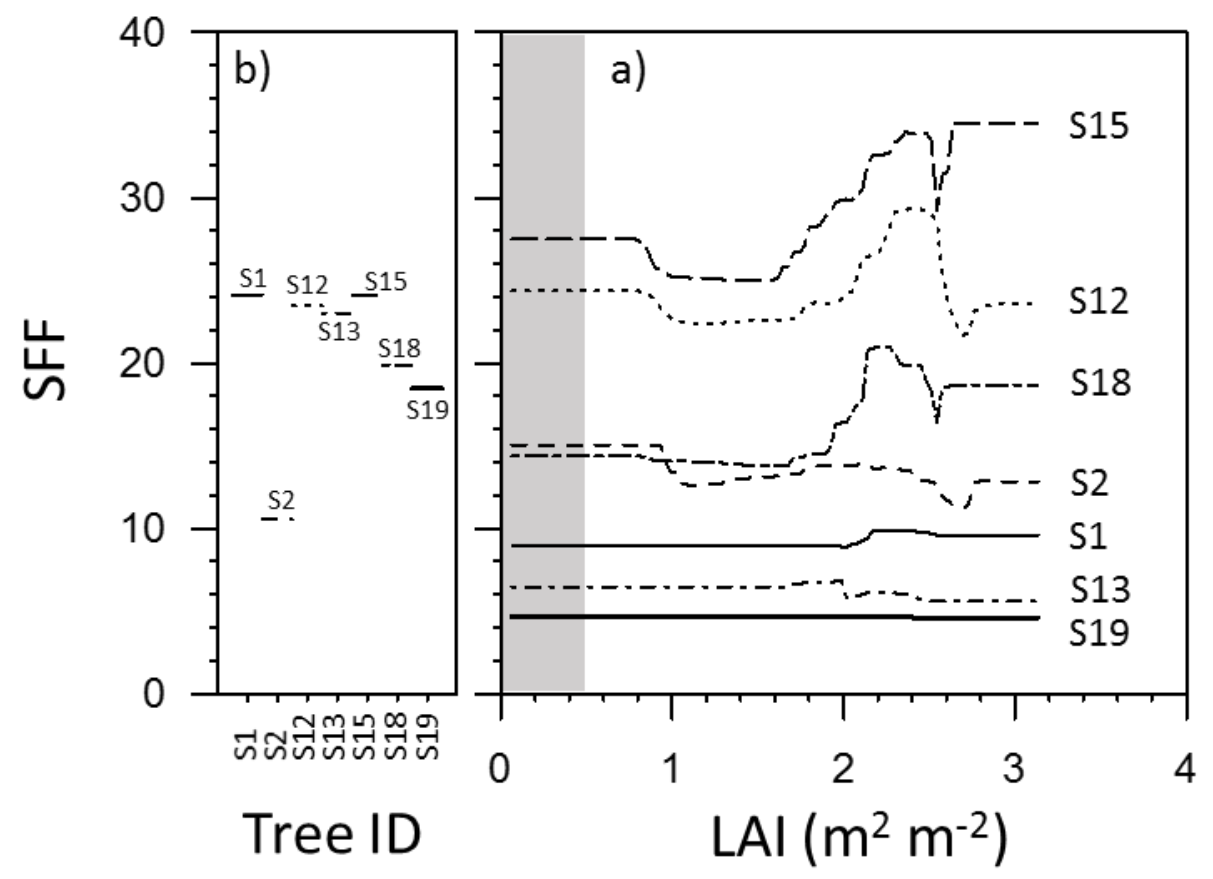

2 Figure 7

3 (a) Comparison of partial dependence plots of LAI between teak individuals where the individual-scale

4 BRT could be performed. Note the differences of the SFFR value in the LAI range from 0 to $0.5 \mathrm{~m}^{2} \mathrm{~m}^{-2}$

5 (shaded) and that plotted in Fig. 4b. Because there were a limited number of SFFR data in the range, the

6 'gbm' package selected large bin sizes for averaging the SFFR when drawing the PDP in the range. (b)

7 The observed median SFFR in the leafless state for each individual for sake of comparison with Fig. 7a. 


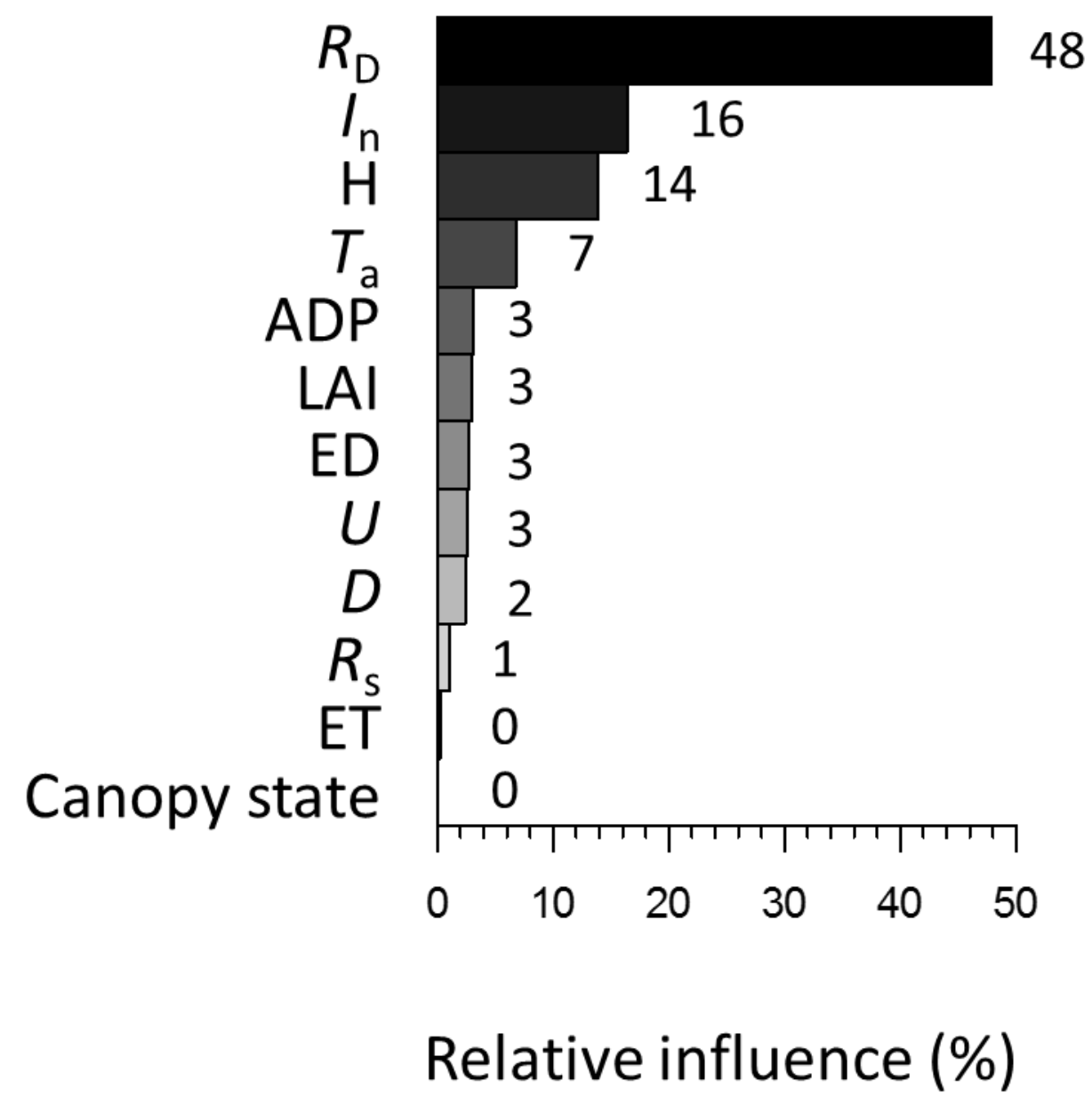

1

2 Figure 8

3 Relative predictor variable influence for stemflow funneling ratio at the stand-scale. Abbreviations in the

4 figure denote rain duration $\left(R_{\mathrm{D}}\right)$, mean rainfall intensity $\left(I_{\mathrm{n}}\right)$, canopy height $(\mathrm{H})$, air temperature $\left(T_{\mathrm{a}}\right)$,

5 antecedent dry period (ADP), leaf area index (LAI), rain event duration (ED), wind speed $(U)$, vapor

6 pressure deficit $(D)$, solar radiation $\left(R_{\mathrm{s}}\right)$ and number of rain events $(\mathrm{ET})$.

7 

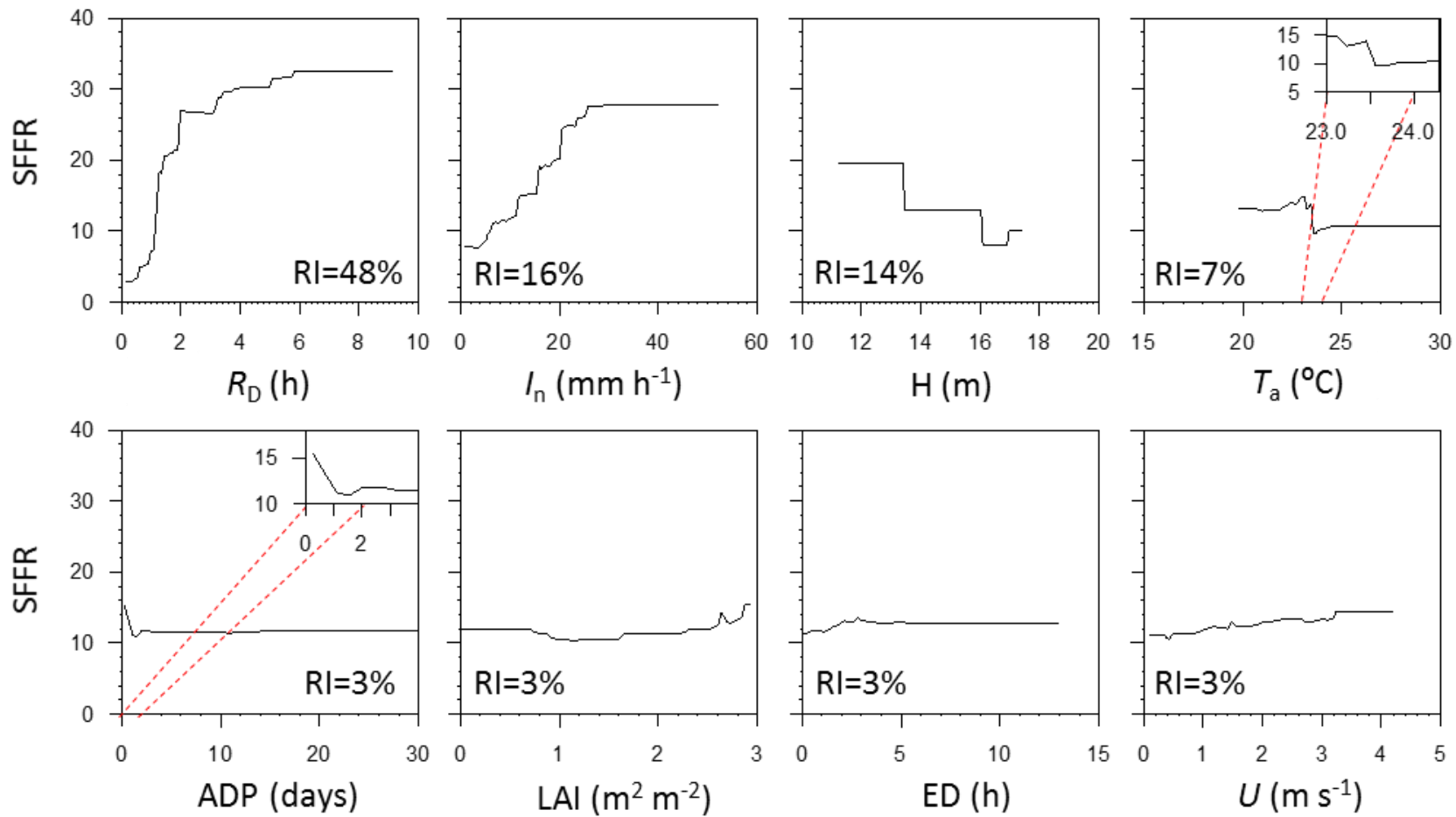

2 Figure 9

3 Partial dependence plots of the predictor variables with a higher rank than 8th and their effect on the

4 stemflow funneling ratio at the stand-scale. Abbreviations in the figure are the same as in Fig. 8. 